\title{
Extended TODIM Based on Cumulative Prospect Theory for Picture Fuzzy Multiple Attribute Group Decision Making
}

\author{
Mengwei $\mathrm{ZHAO}^{1}$, Guiwu WEI ${ }^{1, *}$, Cun $\mathrm{WEI}^{2,3}$, Jiang $\mathrm{WU}^{2}$, \\ Yanfeng $\mathrm{GUO}^{3}$ \\ ${ }^{1}$ School of Business, Sichuan Normal University, Chengdu, 610101, PR China \\ ${ }^{2}$ School of Statistics, Southwestern University of Finance and Economics, Chengdu, 611130, \\ PR China \\ ${ }^{3}$ School of Finance, Southwestern University of Finance and Economics, Chengdu, 610074, \\ PR China \\ e-mail:weiguiwu1973@sicnu.edu.cn
}

Received: February 2020; accepted: April 2020

\begin{abstract}
Picture fuzzy sets (PFSs) utilize the positive, neutral, negative and refusal membership degrees to describe the behaviours of decision-makers in more detail. In this article, we expound the application of extended TODIM based on cumulative prospect theory under picture fuzzy multiple attribute group decision making (MAGDM). In addition, we adopt Information Entropy, which is used to ascertain the weighting vector of attributes to improve the availability of the TODIM method. At last, we exercise the improved TODIM into a numerical case for super market location and testify the effectiveness of this new method by comparing its results with other methods' results.
\end{abstract}

Key words: multiple attribute group decision making (MAGDM), picture fuzzy sets, TODIM, supermarket location.

\section{Introduction}

Multi-attribute decision making method (MADM) and multi-attribute group decision making method (MAGDM) are two essential research directions in the field of modern management decision making. The practical issue of MADM or MAGDM is that decision makers are often confronted with inaccurate description. The complexity of the human brain means that even rational decision makers can be influenced by emotional factors to make vague expressions in the decision-making process. Just as the word "beautiful" is an imprecise expression of fuzzy things, which is prevalent in realistic society. The way to express this reality scientifically has become an important problem for scientists. Thinking about this phenomenon, Zadeh (1965) proposed the concept of fuzzy sets in 1965 to study the inexact phenomena mentioned above by using membership functions. It can be

\footnotetext{
* Corresponding author.
} 
said without exaggeration that fuzzy set is the cornerstone for the research and development of decision making and control. Since then, many researchers have dedicated themselves to the study of fuzziness and uncertainty, greatly developing the fuzzy sets. In 1986, Atanassov (1986) put forward Intuitionistic Fuzzy Sets (IFSs), in which subordinate and non-subordinate functions are integrated to describe uncertain things. In addition, Cuong (2014) introduced degree of neutral subordinate on the basis of IFSs and proposed the concept of picture fuzzy sets (PFSs) in 2014. In addition, many other sets for describing uncertain problems have been proposed and extensively studied (Liu Y. et al., 2019; Zhang et al., 2017; Zhang Z. et al., 2019). However, picture fuzzy set is still irreplaceable and unique in investigating the issues of MADM and MAGDM. Specifically, PFSs have four expressions of membership degree including the positive subordinate degree, neutral subordinate degree, negative subordinate degree and refusal subordinate degree, which is a very detailed breakdown of decision makers' attitudes, corresponding to four descriptions (affirmative, adiaphorous, averse and refusal) when decision makers make a decision (Liang et al., 2018). Because of its excellent characteristics, many scholars use picture fuzzy sets to study decision problems. Ma et al. (2019) gave complex fuzzy sets and extended the range of membership function values. Obviously, compared with other kinds of fuzzy sets, PFSs can delineate the conduct of decision-makers in more detail and are closer to human thinking and cognition of fuzzy things. Therefore, it has more advantages in solving multi-attribute decision making (MADM). Liang et al. (2018) evaluated the cleaner production for gold mines with picture fuzzy information. Meksavang et al. (2019) researched for the selection of sustainable suppliers. Wang et al. (2018) studied the risk evaluation of construction project with PFSs. Khan et al. (2019) invented logarithmic aggregation operators of Picture Fuzzy Numbers to solve MADM problems. Ju et al. (2019) used extended GRP method to study the location of charging stations for electric vehicles under picture fuzzy environment. Sindhu et al. (2019) developed a linear programming model with PFSs. Liu and Zhang (2018) put forward picture fuzzy linguistic set and some aggregation operator based on picture fuzzy information, such as, A-PFLWAA. Wei (2017) also gave some picture fuzzy aggregation operators.

As mentioned above, many great scholars put forward all kinds of methods to study MADM problems, such as MABAC (the distance between the alternatives and the boundary approximation area was defined and introduced by Pamucar and Cirovic (2015) in 2015), VIKOR (a compromising method which was introduced by Opricovic and Tzeng (2004) in 1998), MOORA (proposed by Brauers and Zavadskas (2006) in 1986), TODIM (brought forward by Gomes and Lima (1992) in 1992), EDAS (it was used for calculating the distance of each alternative from the optimal one and presented by Keshavarz Ghorabaee et al. (2015) in 2015) and so on. Among them, the TODIM method is distinctive, which makes use of piecewise function to denote the distance between two schemes. What's more, it is more authentic to take the different attitudes of decision makers towards gains and losses on decision making into consideration by introducing parameter in the process of evaluation. Liang et al. (2020) utilized TODIM to introduce the risk appetite on three-way decisions. Wu Y.N. et al. (2019) investigated the investment selection of meeting the requirements of rooftop distributed photovoltaic projects for industrial and com- 
mercial households with TODIM. Biswas and Sarkar (2019) put forward a kind of methodology based on TODIM. Liang et al. (2019) proposed a mixture TODIM method to assess the risk level of the targets. Zhang Y.X. et al. (2019) explored water safety evaluation on the strength of the TODIM method. Zhang Y.X. et al. (2019) integrated maximizing deviation, FANP and TODIM method. Renet al. (2017) studied TODIM under probabilistic dual hesitant fuzzy environment. Zhu et al. (2019) used grey relational analysis to count the dominance degree. Yuan et al. (2019) got through the ranking of risk level of CFPP investment with TODIM. Liu et al. (2019) generalized TODIM and TOPSIS methods to distance measure. Wu and Zhang (2019) used TODIM under intuitionistic fuzzy environment to obtain the results of product ranking. Wei (2018) accomplished the TODIM in picture fuzzy environment. Mishra and Rani (2018) designed TODIM technique to solve problems in interval-valued IFSs. Zhang et al. (2019) utilized sentiment analysis as well as classical TODIM to evaluate and rank products online in an intuitionistic fuzzy environment. Yu et al. (2017) combined the classical TODIM method with unbalanced hesitant fuzzy linguistic term sets to analyse multi-criteria group decision making. Liang Y.Y. et al. (2019) ameliorated the conventional TODIM with a weight determination method which was based on incomplete weight information. Wang et al. (2019) applied a novel function to TODIM. Liu and Teng (2019) acquired weights by means of probabilistic linguistic information, which extend the TODIM. Tian et al. (2019) developed the traditional TODIM by using Cumulative Prospect Theory (CPT).

The TODIM method based on CPT combines the advantages of traditional TODIM and CPT, providing a more reliable method for studying uncertain decision-making, and makes up for the shortcomings of traditional TODIM method. Unfortunately, we hardly find the use of improved TODIM method based on Cumulative Prospect Theory to study the multi-attribute group decision making (MAGDM) problem in picture fuzzy environment. Hence, the heart of this article is to build a more practical model to resolve the problem of picture fuzzy MAGDM. For achieving this goal, this article pays attention to the psychology of decision makers through a more realistic way to analyse and brings in the entropy weight method to obtain the original weighting vector of attributes, eliminating the subjectivity of the information of attribute weight directly given by the decision maker.

The primary research ideas of this paper are as follows: Section 2 recommends and sorts out the basic knowledge to be used in this paper briefly. In the Section 3, the improved TODIM method is applied to work out the problem of picture fuzzy MAGDM. Section 4 demonstrates the application of the new method and compares it with other approaches to guarantee the availability. Finally, we draw the corresponding conclusions based on the research in this paper, which are shown in Section 5.

\section{Preliminary Knowledge}

In this topic, we review a number of fundamental concepts and methods in regard to picture fuzzy sets as well as extend TODIM based on CPT (Cumulative Prospect Theory). 


\subsection{Picture Fuzzy Sets and Picture Fuzzy Numbers}

Definition 1 (See Garg, 2017). For a non-empty set $O$, Picture Fuzzy Set (PFS) is defined by

$$
L(\mathrm{o})=\left\{\left\langle o, \alpha_{L}(o), \beta_{L}(o), \varphi_{L}(o)\right\rangle \mid o \in O\right\}
$$

where $\alpha_{L}(o) \in[0,1]$ is well-known as degree of positive membership of $L, \varphi_{L}(o) \in[0,1]$ is well-known as degree of negative membership of $L, \beta_{L}(o) \in[0,1]$ is well-known as degree of neutral membership of $L$. In the meantime, $\alpha_{L}(o), \beta_{L}(o)$ and $\varphi_{L}(o)$ satisfy the relation of " $0 \leqslant \alpha_{L}(o)+\beta_{L}(o)+\varphi_{L}(o) \leqslant 1, \forall o \in O$ ". Then the refusal membership of $o$ in $L$ can be calculated by Eq. (2)

$$
z_{L}(o)=1-\alpha_{L}(o)-\beta_{L}(o)-\varphi_{L}(o), \quad \text { for } o \in O .
$$

For convenience, we define the corresponding Picture Fuzzy Number (PFN) $L=$ $\left(\alpha_{L}, \beta_{L}, \varphi_{L}\right)$. And now, let's introduce some algorithms.

Definition 2 (See Meksavang et al., 2019). Let $\delta=\left(\alpha_{\delta}, \beta_{\delta}, \varphi_{\delta}\right)$ and $\varepsilon=\left(\alpha_{\varepsilon}, \beta_{\varepsilon}, \varphi_{\varepsilon}\right)$ represent two PFNs, respectively, then

(1) $\delta \oplus \varepsilon=\left(\alpha_{\delta}+\alpha_{\varepsilon}-\alpha_{\delta} \alpha_{\varepsilon}, \beta_{\delta} \beta_{\varepsilon}, \varphi_{\delta} \varphi_{\varepsilon}\right)$;

(2) $\delta \otimes \varepsilon=\left(\alpha_{\delta} \alpha_{\varepsilon}, \beta_{\delta}+\beta_{\varepsilon}-\beta_{\delta} \beta_{\varepsilon}, \varphi_{\delta}+\varphi_{\varepsilon}-\varphi_{\delta} \varphi_{\varepsilon}\right)$;

(3) $\omega \cdot \delta=\left(1-\left(1-\alpha_{\delta}\right)^{\omega},\left(\beta_{\delta}\right)^{\omega},\left(\varphi_{\delta}\right)^{\omega}\right), \omega>0$;

(4) $\delta^{\omega}=\left(\left(\alpha_{\delta}\right)^{\omega}, 1-\left(1-\beta_{\delta}\right)^{\omega}, 1-\left(1-\varphi_{\delta}\right)^{\omega}\right), \omega>0$;

(5) $\bar{\delta}=\left(\varphi_{\delta}, \beta_{\delta}, \alpha_{\delta}\right)$.

Definition 3 (See Wei, 2018). If $L=\left(\alpha_{L}, \beta_{L}, \varphi_{L}\right)$ is a PFN, there will be the score function $c_{L}$ and accuracy function $p_{L}$, which can be computed by Eqs. (3) and (4).

$$
\begin{array}{ll}
c_{L}=\frac{1+\alpha_{L}-\varphi_{L}}{2}, & c_{L} \in[0,1], \\
p_{L}=\alpha_{L}+\beta_{L}+\varphi_{L}, & p_{L} \in[0,1] .
\end{array}
$$

Definition 4 (See Liang et al., 2018). If $\delta=\left(\alpha_{\delta}, \beta_{\delta}, \varphi_{\delta}\right)$ and $\varepsilon=\left(\alpha_{\varepsilon}, \beta_{\varepsilon}, \varphi_{\varepsilon}\right)$ are two PFNs, respectively, their relationships of size are as follows:

(1) When $c_{\delta}>c_{\varepsilon}$, then $\delta>\varepsilon$.

(2) When $c_{\delta}=c_{\varepsilon}$, if $p_{\delta}>p_{\varepsilon}$, then $\delta>\varepsilon$; if $p_{\delta}=p_{\varepsilon}$, then $\delta=\varepsilon$.

Definition 5 (See Meksavang et al., 2019). Let $\delta=\left(\alpha_{\delta}, \beta_{\delta}, \varphi_{\delta}\right)$ and $\varepsilon=\left(\alpha_{\varepsilon}, \beta_{\varepsilon}, \varphi_{\varepsilon}\right)$ represent two PFNs, respectively, then their distance is counted by:

$$
\begin{aligned}
d(\delta, \varepsilon)= & \frac{1}{4}\left(\left|\alpha_{\delta}-\alpha_{\varepsilon}\right|+\left|\beta_{\delta}-\beta_{\varepsilon}\right|+\left|\varphi_{\delta}-\varphi_{\varepsilon}\right|+\left|z_{\delta}-z_{\varepsilon}\right|\right) \\
& +\frac{1}{2} \max \left(\left|\alpha_{\delta}-\alpha_{\varepsilon}\right|+\left|\beta_{\delta}-\beta_{\varepsilon}\right|+\left|\varphi_{\delta}-\varphi_{\varepsilon}\right|+\left|z_{\delta}-z_{\varepsilon}\right|\right) .
\end{aligned}
$$




\subsection{Extended TODIM Method Based on Cumulative Prospect Theory}

The original TODIM, which was proposed by Gomes and Lima (1992), utilizes the dominance degree of each alternative over the other alternatives to select the optimal project. At present, this method has extensive use in Multiple Attribute Decision Making (MADM) and other areas. Nonetheless, this method is unable to acquire the weight of attributes, using the weighting function. So, XU, TIAN, and GU improved classical TODIM and demonstrated extended TODIM on the Basis of Cumulative Prospect Theory. Meanwhile, they show the application of extended TODIM in real-valued MADM. In what follows, we introduce this extended TODIM method.

In the following decision matrix $N$, the alternatives and attributes are displayed in accordance with decision maker's view.

$$
N=\left[\begin{array}{cccccc}
n_{11} & n_{12} & \cdots & n_{1 r} & \cdots & n_{1 g} \\
n_{21} & n_{22} & \cdots & n_{2 r} & \cdots & n_{2 g} \\
\vdots & \vdots & \ddots & \vdots & \ddots & \vdots \\
n_{s 1} & n_{s 2} & \cdots & n_{s r} & \cdots & n_{s g} \\
\vdots & \vdots & \ddots & \vdots & \ddots & \vdots \\
n_{f 1} & n_{f 2} & \cdots & n_{f r} & \cdots & n_{f g}
\end{array}\right]=\left(n_{s r}\right)_{f \times g}
$$

$\lambda=\left(\lambda_{1}, \lambda_{2}, \ldots, \lambda_{g}\right)$ represents the weighting vector of attributes, which satisfies $\sum_{r=1}^{g} \lambda_{r}=1$.

Step 1. The converted probability of the alternative $V_{i}$ to $V_{k}$ will be computed according to (6) or (7), where $i, k \in f$ and $i \neq k$.

When $n_{i r}-n_{k r} \geqslant 0$, the converted probability weight is calculated by (6):

$$
\eta_{i k r}^{+}\left(\lambda_{r}\right)=\lambda_{r}^{\zeta} /\left(\lambda_{r}^{\zeta}+\left(1-\lambda_{r}\right)^{\zeta}\right)^{\frac{1}{\zeta}}
$$

Otherwise, the converted probability weight is calculated by (7):

$$
\eta_{i k r}^{-}\left(\lambda_{r}\right)=\lambda_{r}^{\xi} /\left(\lambda_{r}^{\xi}+\left(1-\lambda_{r}\right)^{\xi}\right)^{\frac{1}{\xi}}
$$

where $\zeta$ and $\xi$ are the parameters describing the curvature of the weighting function.

Step 2. Eq. (8) is used to determine the relative weight $\eta_{i k r}^{*}\left(\lambda_{r}\right)$ of the alternative $V_{i}$ to $V_{k}$.

$$
\eta_{i k r}^{*}\left(\lambda_{r}\right)=\eta_{i k r}\left(\lambda_{r}\right) / \max \left\{\eta_{i k r}\left(\lambda_{p}\right) \mid p \in g\right\}, \quad r \in g, \forall(i, k)
$$

where $\eta_{i k r}\left(\lambda_{r}\right)$ represents the converted probability weight of the $r$ th attribute for the alternative $V_{i}$, which is equal to $\eta_{i k r}^{+}\left(\lambda_{r}\right)$ when $n_{i r} \geqslant n_{k r}$, or equal to $\eta_{i k r}^{-}\left(\lambda_{r}\right)$ according to $(7)$. 
Step 3. Figure out the relative prospect dominance of alternative $V_{i}$ to $V_{k}$ underneath the attribute $r$ with (9):

$$
\vartheta_{r}\left(V_{i}, V_{k}\right)= \begin{cases}\eta_{i k r}^{*}\left(\lambda_{r}\right) \cdot\left(n_{i r}-n_{k r}\right)^{\beta} / \sum_{r=1}^{g} \eta_{i k r}^{*}\left(\lambda_{r}\right), & \text { if } n_{i r}>n_{k r} \\ 0, & \text { if } n_{i r}=n_{k r} \\ -\theta\left(\sum_{r=1}^{g} \eta_{i k r}^{*}\left(\lambda_{r}\right)\right) \cdot\left(n_{k r}-n_{i r}\right)^{\alpha} / \eta_{i k r}^{*}\left(\lambda_{r}\right), & \text { if } n_{i r}<n_{k r}\end{cases}
$$

where $\alpha, \beta$ and $\theta$ are the parameters.

Step 4. Determine the dominance degree of the alternative $V_{i}$ over the others, which is calculated as Eq. (10).

$$
\pi\left(V_{i}\right)=\sum_{k=1}^{f} \sum_{r=1}^{g} \vartheta_{r}\left(V_{i}, V_{k}\right), \quad i=1,2, \ldots, f
$$

Step 5. Acquire the overall dominance degree of the alternative $V_{i}$ from Eq. (11).

$$
\psi\left(V_{i}\right)=\frac{\pi\left(V_{i}\right)-\min _{i}\left\{\pi\left(V_{i}\right)\right\}}{\max _{i}\left\{\pi\left(V_{i}\right)\right\}-\min _{i}\left\{\pi\left(V_{i}\right)\right\}}, \quad i=1,2, \ldots, f .
$$

Step 6. Rank the overall dominance degree $\psi\left(V_{i}\right), i \in f$. The alternative with the bigger $\psi\left(V_{i}\right)$ value is considered the better choice.

\section{Extended TODIM for Picture Fuzzy MAGDM Based on Cumulative Prospect Theory}

Let $V=\left\{V_{1}, V_{2}, \ldots, V_{f}\right\}$ and $D=\left\{D_{1}, D_{2}, \ldots, D_{g}\right\}$ be the sets of alternatives and attributes, respectively, and the information about the attribute weights is unknown. Now, there are $n$ decision makers, integrated into the set of decision makers $M=$ $\left\{M_{1}, M_{2}, \ldots, M_{n}\right\}$, whose weight vector is $\chi=\left(\chi_{1}, \chi_{2}, \ldots, \chi_{n}\right), \chi_{t} \geqslant 0,(t=1,2$, $\ldots, n), \sum_{t=1}^{n} \chi_{t}=1$.

$N^{t}=\left(n_{s r}^{t}\right)_{f \times g}=\left(\alpha_{s r}^{t}, \beta_{s r}^{t}, \varphi_{s r}^{t}\right)_{f \times g}$ is the decision matrix under picture fuzzy environment of the $t$ th decider, where $\alpha_{s r}^{t}$ indicates the positive subordinate degree of the $t$ th decision maker, $\beta_{s r}^{t}$ expresses the neutral subordinate degree of the $t$ th decision maker, $\varphi_{s r}^{t}$ expresses the negative subordinate degree of the $t$ th decision maker, $\alpha_{s r}^{t}, \beta_{s r}^{t}, \varphi_{s r}^{t} \in[0,1]$ and $0 \leqslant \alpha_{s r}^{t}+\beta_{s r}^{t}+\varphi_{s r}^{t} \leqslant 1, s=1,2, \ldots, f, r=1,2, \ldots, g, t=1,2, \ldots, n$.

In the following, we introduce Picture Fuzzy MAGDM using extended TODIM. The framework is shown in Fig. 1.

Step 1. Transform the cost attributes into the benefit attributes by using Eq. (12).

$$
\begin{aligned}
& U^{t}=\left(u_{s r}^{t}\right)_{f \times g}, \quad s=1,2, \ldots, f, r=1,2, \ldots, g, t=1,2, \ldots, n, \\
& u_{s r}^{t}=\left(\mu_{s r}^{t}, v_{s r}^{t}, \rho_{s r}^{t}\right)= \begin{cases}n_{s r}^{t}=\left(\alpha_{s r}^{t}, \beta_{s r}^{t}, \varphi_{s r}^{t}\right), & D_{r} \text { is a benefit attribute, } \\
\bar{n}_{s r}^{t}=\left(\varphi_{s r}^{t}, \beta_{s r}^{t}, \alpha_{s r}^{t}\right), & D_{r} \text { is a cost attribute. }\end{cases}
\end{aligned}
$$




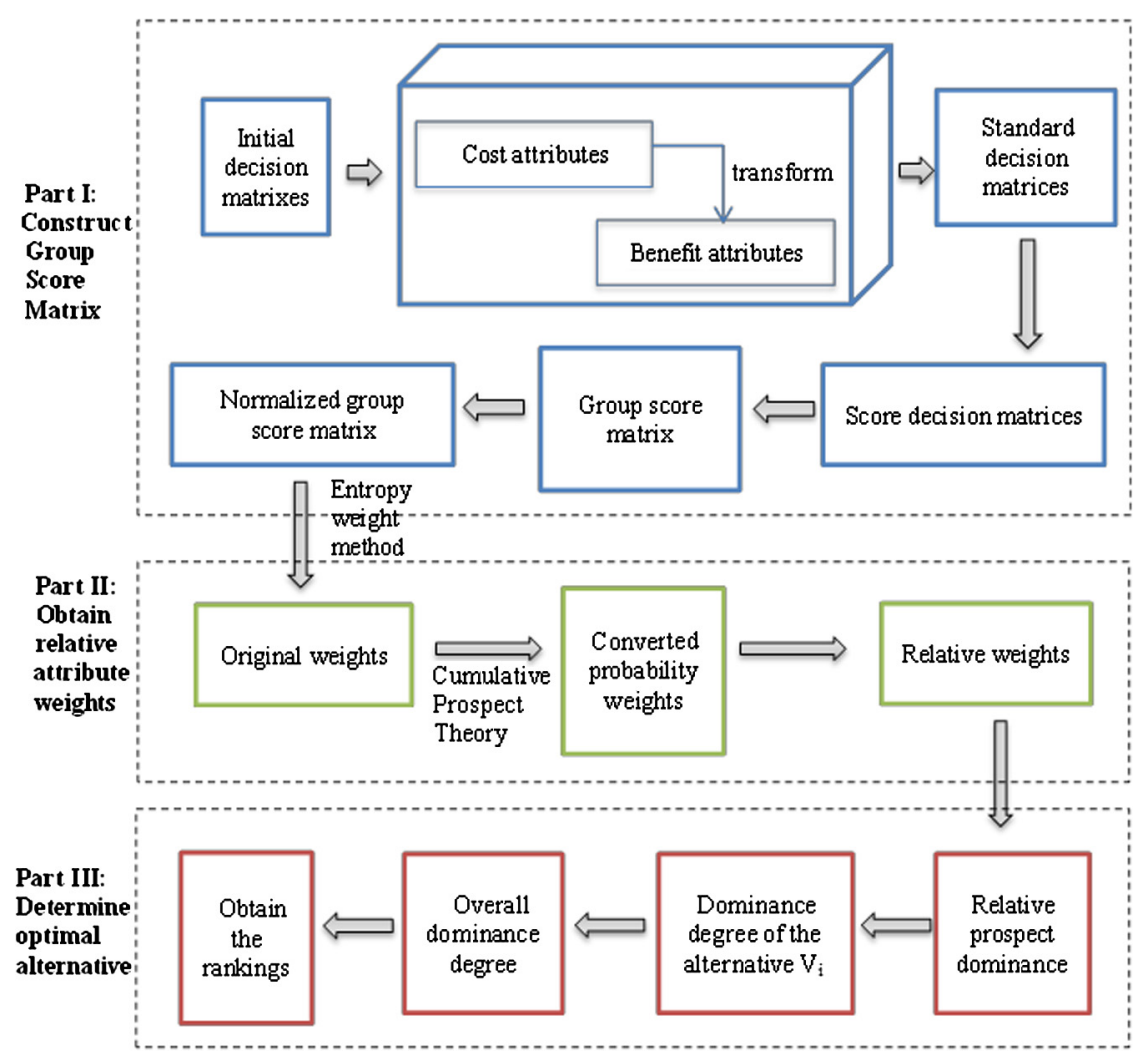

Fig. 1. The flow chart of extended TODIM for picture fuzzy MAGDM based on cumulative prospect theory.

Step 2. Calculate score matrix $C^{t}=\left(c_{s r}^{t}\right)_{f \times g}$ for each normalized decision maker using Eq. (13), and integrate these score matrices for different decision maker into one group score matrix $Y=\left(y_{s r}\right)_{f \times g}$ using Eq. (14).

$$
\begin{aligned}
c_{s r}^{t} & =\frac{\left(1+\mu_{s r}^{t}-\rho_{s r}^{t}\right)}{2}, \quad s=1,2, \ldots, f, r=1,2, \ldots, g, t=1,2, \ldots, n, \\
y_{s r} & =\sum_{t=1}^{n} \chi_{t} c_{s r}^{t}, \quad s=1,2, \ldots, f, r=1,2, \ldots, g .
\end{aligned}
$$

Step 3. Use Eq. (15) to normalize the group score matrix and obtain the normalized matrix $X=\left(x_{s r}\right)_{f \times g}$.

$$
x_{s r}=\frac{y_{s r}}{\sum_{s=1}^{f} y_{s r}}, \quad r=1,2, \ldots, g .
$$

Step 4. Utilize the Entropy Weight Method to obtain the original weight attributes $\lambda=$ $\left(\lambda_{1}, \lambda_{2}, \ldots, \lambda_{n}\right), \lambda_{r} \geqslant 0$, which is calculated as (16) and (17): 


$$
\begin{aligned}
& E_{r}=-\frac{1}{\ln f} \sum_{s=1}^{f}\left(x_{s r} \ln x_{s r}\right), \quad r=1,2, \ldots, g, 0 \leqslant E_{r} \leqslant 1, \\
& \lambda_{r}=\frac{1-E_{r}}{\sum_{r=1}^{g}\left(1-E_{r}\right)}, \quad r=1,2, \ldots, g .
\end{aligned}
$$

Step 5. The converted probability of the alternative $V_{i}$ to $V_{k}$ will be computed according to (18) or (19), where $i, k \in f$ and $i \neq k$.

When $x_{i r}-x_{k r} \geqslant 0$, the converted probability weight is calculated by (18):

$$
\eta_{i k r}^{+}\left(\lambda_{r}\right)=\lambda_{r}^{\zeta} /\left(\lambda_{r}^{\zeta}+\left(1-\lambda_{r}\right)^{\zeta}\right)^{\frac{1}{\zeta}}
$$

Otherwise, the converted probability weight is calculated by (19):

$$
\eta_{i k r}^{-}\left(\lambda_{r}\right)=\lambda_{r}^{\xi} /\left(\lambda_{r}^{\xi}+\left(1-\lambda_{r}\right)^{\xi}\right)^{\frac{1}{\xi}}
$$

where $\zeta$ and $\xi$ are the parameters describing the curvature of the weighting function.

Step 6. Eq. (20) is used to determine the relative weight $\eta_{i k r}^{*}\left(\lambda_{r}\right)$ of the alternative $V_{i}$ to $V_{k}$.

$$
\eta_{i k r}^{*}\left(\lambda_{r}\right)=\eta_{i k r}\left(\lambda_{r}\right) / \max \left\{\eta_{i k r}\left(\lambda_{p}\right) \mid p \in g\right\}, \quad r \in g, \forall(i, k),
$$

where $\eta_{i k r}\left(\lambda_{r}\right)$ represents the converted probability weight of the $r$ th attribute for the alternative $V_{i}$, which is equal to $\eta_{i k r}^{+}\left(\lambda_{r}\right)$ when $x_{i r} \geqslant x_{k r}$, or equal to $\eta_{i k r}^{-}\left(\lambda_{r}\right)$ according to Eq. (19).

Step 7. Determine the dominance degree of the alternative $V_{i}$ over the others, which is calculated as Eq. (21):

$$
\pi\left(V_{i}\right)=\sum_{k=1}^{f} \sum_{r=1}^{g} \vartheta_{r}\left(V_{i}, V_{k}\right), \quad i=1,2, \ldots, f
$$

where

$$
\vartheta_{r}\left(V_{i}, V_{k}\right)= \begin{cases}\eta_{i k r}^{*}\left(\lambda_{r}\right) \cdot\left(x_{i r}-x_{k r}\right)^{\beta} / \sum_{r=1}^{g} \eta_{i k r}^{*}\left(\lambda_{r}\right), & \text { if } x_{i r}>x_{k r}, \\ 0, & \text { if } x_{i r}=x_{k r}, \\ -\theta\left(\sum_{r=1}^{g} \eta_{i k r}^{*}\left(\lambda_{r}\right)\right) \cdot\left(x_{k r}-x_{i r}\right)^{\alpha} / \eta_{i k r}^{*}\left(\lambda_{r}\right), & \text { if } x_{i r}<x_{k r} .\end{cases}
$$

The $\vartheta_{r}\left(V_{i}, V_{k}\right)$ indicates the relative prospect dominance of alternative $V_{i}$ to $V_{k}$ under the attribute $r$, and $\alpha, \beta$ and $\theta$ are the parameters.

Step 8. Acquire the overall dominance degree of the alternative $V_{i}$ from Eq. (23).

$$
\psi\left(V_{i}\right)=\frac{\pi\left(V_{i}\right)-\min _{i}\left\{\pi\left(V_{i}\right)\right\}}{\max _{i}\left\{\pi\left(V_{i}\right)\right\}-\min _{i}\left\{\pi\left(V_{i}\right)\right\}}, \quad i=1,2, \ldots, f .
$$


Table 1

Decision matrix $N^{1}$ given by the first expert.

\begin{tabular}{llllll}
\hline & $D_{1}$ & $D_{2}$ & $D_{3}$ & $D_{4}$ & $D_{5}$ \\
\hline$V_{1}$ & $(0.28,0.06,0.54)$ & $(0.86,0.03,0.11)$ & $(0.55,0.13,0.26)$ & $(0.24,0.08,0.63)$ & $(0.56,0.18,0.22)$ \\
$V_{2}$ & $(0.26,0.19,0.48)$ & $(0.53,0.12,0.03)$ & $(0.52,0.18,0.21)$ & $(0.21,0.16,0.53)$ & $(0.75,0.05,0.12)$ \\
$V_{3}$ & $(0.15,0.02,0.72)$ & $(0.74,0.06,0.05)$ & $(0.70,0.04,0.13)$ & $(0.17,0.04,0.74)$ & $(0.61,0.21,0.08)$ \\
$V_{4}$ & $(0.22,0.13,0.58)$ & $(0.69,0.21,0.08)$ & $(0.64,0.16,0.08)$ & $(0.16,0.24,0.59)$ & $(0.46,0.31,0.13)$ \\
\hline
\end{tabular}

Step 9. Rank the overall dominance degree $\psi\left(V_{i}\right), i \in f$. The alternative with the bigger $\psi\left(V_{i}\right)$ value is considered a better choice.

\section{Numerical Instance}

\subsection{Numerical Example for Picture Fuzzy MAGDM}

China's accession to the world trade organization has continued for ten years, the retail circulation market has gradually opened to foreign investment, so that China's local retail enterprises are facing the challenge of international retail giants. In the past period of time, with the continuous improvement of China's urbanization level, community business has been developing vigorously. As a new type of business organization, community supermarket has become the focus of many retail manufacturers. However, many supermarkets are blind in site selection and lack scientific site selection research, which leads to high cost input and low benefit level, and eventually they are eliminated by the market. How to scientifically study and draw the relationship between the factors influencing the reasonable location of the supermarket, related to the future development of retail enterprises imminent problem. With the spring of Internet economy, the competition of real economy is more and more fierce. The supermarket location selection could be regarded as a MAGDM problem (Gao et al., 2020; Lu et al., 2019; Wang P. et al., 2019; Wei et al., 2019a). Therefore, it is crucial for a supermarket to select the best location that may result in prodigious effectiveness. Now, for the management of a supermarket, there are four site locations $V_{i}(i=1,2,3,4)$ from which to choose. And the management adopts five attributes to assess these four alternatives: (1) $D_{1}$ is the shop rent, (2) $D_{2}$ is the population density, (3) $D_{3}$ is the consumption level, (4) $D_{4}$ is the intensity of competitive rivalry, (5) $D_{5}$ is the transportation convenience. Among them, $D_{1}$ and $D_{4}$ are cost attributes, and the others are benefit attributes. The four store location plans are going to be evaluated by three experts (whose weighting vector is $\left.\chi=\left(\chi_{1}, \chi_{2}, \chi_{3}\right)^{T}=(0.43,0.22,0.35)^{T}\right)$ using PFNs under five attributes. Then, the picture fuzzy decision matrices which are given by the three experts are shown below (see Tables 1-3).

In the rest of the paper, we introduce using the suggested approach in this article obtaining the optimal location.

Step 1. Use Eq. (12) to transform cost into benefit. The result is shown in Tables 4 to 6.

Step 2. Calculate score matrix $C^{t}=\left(c_{s r}^{t}\right)_{4 \times 5}$ for each normalized decision maker using Eq. (13), and it is shown in Table 7 to Table 9. Then, integrate these score matrices for 
Table 2

Decision matrix $N^{2}$ given by the second expert.

\begin{tabular}{llllll}
\hline & $D_{1}$ & $D_{2}$ & $D_{3}$ & $D_{4}$ & $D_{5}$ \\
\hline$V_{1}$ & $(0.28,0.06,0.62)$ & $(0.87,0.03,0.09)$ & $(0.71,0.05,0.20)$ & $(0.33,0.14,0.49)$ & $(0.58,0.14,0.16)$ \\
$V_{2}$ & $(0.22,0.16,0.52)$ & $(0.47,0.14,0.26)$ & $(0.62,0.13,0.25)$ & $(0.12,0.22,0.48)$ & $(0.65,0.13,0.15)$ \\
$V_{3}$ & $(0.19,0.11,0.67)$ & $(0.69,0.05,0.21)$ & $(0.84,0.02,0.13)$ & $(0.09,0.23,0.62)$ & $(0.63,0.05,0.25)$ \\
$V_{4}$ & $(0.02,0.08,0.74)$ & $(0.62,0.12,0.04)$ & $(0.58,0.26,0.14)$ & $(0.24,0.02,0.71)$ & $(0.52,0.17,0.24)$ \\
\hline
\end{tabular}

Table 3

Decision matrix $N^{3}$ given by the third expert.

\begin{tabular}{llllll}
\hline & $D_{1}$ & $D_{2}$ & $D_{3}$ & $D_{4}$ & $D_{5}$ \\
\hline$V_{1}$ & $(0.14,0.28,0.52)$ & $(0.68,0.02,0.16)$ & $(0.67,0.06,0.23)$ & $(0.21,0.09,0.66)$ & $(0.47,0.11,0.26)$ \\
$V_{2}$ & $(0.13,0.15,0.68)$ & $(0.58,0.24,0.16)$ & $(0.43,0.38,0.12)$ & $(0.15,0.26,0.48)$ & $(0.65,0.08,0.16)$ \\
$V_{3}$ & $(0.11,0.03,0.77)$ & $(0.73,0.09,0.13)$ & $(0.65,0.12,0.22)$ & $(0.16,0.08,0.72)$ & $(0.59,0.04,0.35)$ \\
$V_{4}$ & $(0.21,0.09,0.66)$ & $(0.56,0.07,0.26)$ & $(0.49,0.21,0.26)$ & $(0.28,0.03,0.54)$ & $(0.53,0.22,0.23)$ \\
\hline
\end{tabular}

Table 4

Normalized decision matrix $U^{1}$ given by the first expert.

\begin{tabular}{llllll}
\hline & $D_{1}$ & $D_{2}$ & $D_{3}$ & $D_{4}$ & $D_{5}$ \\
\hline$V_{1}$ & $(0.54,0.06,0.28)$ & $(0.86,0.03,0.11)$ & $(0.55,0.13,0.26)$ & $(0.63,0.08,0.24)$ & $(0.56,0.18,0.22)$ \\
$V_{2}$ & $(0.48,0.19,0.26)$ & $(0.53,0.12,0.03)$ & $(0.52,0.18,0.21)$ & $(0.53,0.16,0.21)$ & $(0.75,0.05,0.12)$ \\
$V_{3}$ & $(0.72,0.02,0.15)$ & $(0.74,0.06,0.05)$ & $(0.70,0.04,0.13)$ & $(0.74,0.04,0.17)$ & $(0.61,0.21,0.08)$ \\
$V_{4}$ & $(0.58,0.13,0.22)$ & $(0.69,0.21,0.08)$ & $(0.64,0.16,0.08)$ & $(0.59,0.24,0.16)$ & $(0.46,0.31,0.13)$ \\
\hline
\end{tabular}

Table 5

Normalized decision matrix $U^{2}$ given by the second expert

\begin{tabular}{llllll}
\hline & $D_{1}$ & $D_{2}$ & $D_{3}$ & $D_{4}$ & $D_{5}$ \\
\hline$V_{1}$ & $(0.62,0.06,0.28)$ & $(0.87,0.03,0.09)$ & $(0.71,0.05,0.20)$ & $(0.49,0.14,0.33)$ & $(0.58,0.14,0.16)$ \\
$V_{2}$ & $(0.52,0.16,0.22)$ & $(0.47,0.14,0.26)$ & $(0.62,0.13,0.25)$ & $(0.48,0.22,0.12)$ & $(0.65,0.13,0.15)$ \\
$V_{3}$ & $(0.67,0.11,0.19)$ & $(0.69,0.05,0.21)$ & $(0.84,0.02,0.13)$ & $(0.62,0.23,0.09)$ & $(0.63,0.05,0.25)$ \\
$V_{4}$ & $(0.74,0.08,0.02)$ & $(0.62,0.12,0.04)$ & $(0.58,0.26,0.14)$ & $(0.71,0.02,0.24)$ & $(0.52,0.17,0.24)$ \\
\hline
\end{tabular}

Table 6

Normalized decision matrix $U^{3}$ given by the third expert.

\begin{tabular}{llllll}
\hline & $D_{1}$ & $D_{2}$ & $D_{3}$ & $D_{4}$ & $D_{5}$ \\
\hline$V_{1}$ & $(0.52,0.28,0.14)$ & $(0.68,0.02,0.16)$ & $(0.67,0.06,0.23)$ & $(0.66,0.09,0.21)$ & $(0.47,0.11,0.26)$ \\
$V_{2}$ & $(0.68,0.15,0.13)$ & $(0.58,0.24,0.16)$ & $(0.43,0.38,0.12)$ & $(0.48,0.26,0.15)$ & $(0.65,0.08,0.16)$ \\
$V_{3}$ & $(0.77,0.03,0.11)$ & $(0.73,0.09,0.13)$ & $(0.65,0.12,0.22)$ & $(0.72,0.08,0.16)$ & $(0.59,0.04,0.35)$ \\
$V_{4}$ & $(0.66,0.09,0.21)$ & $(0.56,0.07,0.26)$ & $(0.49,0.21,0.26)$ & $(0.54,0.03,0.28)$ & $(0.53,0.22,0.23)$ \\
\hline
\end{tabular}

different decision maker into one group score matrix $Y=\left(y_{s r}\right)_{4 \times 5}$ using Eq. (14). The result is shown in Table 10.

Step 3. Use Eq. (15) to normalize the group score matrix and obtain the normalized matrix $X=\left(x_{s r}\right)_{4 \times 5}$ shown in Table 11 . 
Table 7

Score matrix $C^{1}$ given by the first expert.

\begin{tabular}{llllll}
\hline & $D_{1}$ & $D_{2}$ & $D_{3}$ & $D_{4}$ & $D_{5}$ \\
\hline$V_{1}$ & 0.6300 & 0.8750 & 0.6450 & 0.6950 & 0.6700 \\
$V_{2}$ & 0.6100 & 0.7500 & 0.6550 & 0.6600 & 0.8150 \\
$V_{3}$ & 0.7850 & 0.8450 & 0.7850 & 0.7850 & 0.7650 \\
$V_{4}$ & 0.6800 & 0.8050 & 0.7800 & 0.7150 & 0.6650 \\
\hline
\end{tabular}

Table 8

Score matrix $C^{2}$ given by the second expert.

\begin{tabular}{llllll}
\hline & $D_{1}$ & $D_{2}$ & $D_{3}$ & $D_{4}$ & $D_{5}$ \\
\hline$V_{1}$ & 0.6700 & 0.8900 & 0.7550 & 0.5800 & 0.7100 \\
$V_{2}$ & 0.6500 & 0.6050 & 0.6850 & 0.6800 & 0.7500 \\
$V_{3}$ & 0.7400 & 0.7400 & 0.8550 & 0.7650 & 0.6900 \\
$V_{4}$ & 0.8600 & 0.7900 & 0.7200 & 0.7350 & 0.6400 \\
\hline
\end{tabular}

Table 9

Score matrix $C^{3}$ given by the third expert.

\begin{tabular}{llllll}
\hline & $D_{1}$ & $D_{2}$ & $D_{3}$ & $D_{4}$ & $D_{5}$ \\
\hline$V_{1}$ & 0.6900 & 0.7600 & 0.7200 & 0.7250 & 0.6050 \\
$V_{2}$ & 0.7750 & 0.7100 & 0.6550 & 0.6650 & 0.7450 \\
$V_{3}$ & 0.8300 & 0.8000 & 0.7150 & 0.7800 & 0.6200 \\
$V_{4}$ & 0.7250 & 0.6500 & 0.6150 & 0.6300 & 0.6500 \\
\hline
\end{tabular}

Table 10

Group score matrix $Y$.

\begin{tabular}{llllll}
\hline & $D_{1}$ & $D_{2}$ & $D_{3}$ & $D_{4}$ & $D_{5}$ \\
\hline$V_{1}$ & 0.6598 & 0.8381 & 0.6955 & 0.6802 & 0.6561 \\
$V_{2}$ & 0.6766 & 0.7041 & 0.6616 & 0.6662 & 0.7762 \\
$V_{3}$ & 0.7909 & 0.8062 & 0.7759 & 0.7789 & 0.6978 \\
$V_{4}$ & 0.7354 & 0.7475 & 0.7091 & 0.6897 & 0.6543 \\
\hline
\end{tabular}

Table 11

Normalized Group score matrix $X$.

\begin{tabular}{llllll}
\hline & $D_{1}$ & $D_{2}$ & $D_{3}$ & $D_{4}$ & $D_{5}$ \\
\hline$V_{1}$ & 0.2305 & 0.2707 & 0.2447 & 0.2416 & 0.2356 \\
$V_{2}$ & 0.2363 & 0.2274 & 0.2328 & 0.2367 & 0.2788 \\
$V_{3}$ & 0.2763 & 0.2604 & 0.2730 & 0.2767 & 0.2506 \\
$V_{4}$ & 0.2569 & 0.2414 & 0.2495 & 0.2450 & 0.2350 \\
\hline
\end{tabular}

Step 4. Utilize Eq. (16) and (17) to obtain the original weighting vector of attributes $\lambda=$ $(0.2368,0.2054,0.1546,0.1765,0.2266)$.

Step 5. Compute the converted probability of the alternative $V_{i}$ to $V_{k}$ according to (18) or (19). The result is shown in Tables 12 to $15(\zeta=0.61, \xi=0.69$, which derive from the experiment of Kahneman, 1992). 
Table 12

The converted probability of the alternative $V_{1}$ to others.

\begin{tabular}{llllll}
\hline & $D_{1}$ & $D_{2}$ & $D_{3}$ & $D_{4}$ & $D_{5}$ \\
\hline$\eta_{12}$ & 0.2842 & 0.2642 & 0.2303 & 0.2455 & 0.2768 \\
$\eta_{13}$ & 0.2842 & 0.2642 & 0.2207 & 0.2387 & 0.2768 \\
$\eta_{14}$ & 0.2842 & 0.2642 & 0.2207 & 0.2387 & 0.2771 \\
\hline
\end{tabular}

Table 13

The converted probability of the alternative $V_{2}$ to others.

\begin{tabular}{llllll}
\hline & $D_{1}$ & $D_{2}$ & $D_{3}$ & $D_{4}$ & $D_{5}$ \\
\hline$\eta_{21}$ & 0.2831 & 0.2611 & 0.2207 & 0.2387 & 0.2771 \\
$\eta_{23}$ & 0.2842 & 0.2611 & 0.2207 & 0.2387 & 0.2771 \\
$\eta_{24}$ & 0.2842 & 0.2611 & 0.2207 & 0.2387 & 0.2771 \\
\hline
\end{tabular}

Table 14

The converted probability of the alternative $V_{3}$ to others.

\begin{tabular}{llllll}
\hline & $D_{1}$ & $D_{2}$ & $D_{3}$ & $D_{4}$ & $D_{5}$ \\
\hline$\eta_{31}$ & 0.2831 & 0.2611 & 0.2303 & 0.2455 & 0.2771 \\
$\eta_{32}$ & 0.2831 & 0.2642 & 0.2303 & 0.2455 & 0.2768 \\
$\eta_{34}$ & 0.2831 & 0.2642 & 0.2303 & 0.2455 & 0.2771 \\
\hline
\end{tabular}

Table 15

The converted probability of the alternative $V_{4}$ to others.

\begin{tabular}{llllll}
\hline & $D_{1}$ & $D_{2}$ & $D_{3}$ & $D_{4}$ & $D_{5}$ \\
\hline$\eta_{41}$ & 0.2831 & 0.2611 & 0.2303 & 0.2455 & 0.2768 \\
$\eta_{42}$ & 0.2831 & 0.2642 & 0.2303 & 0.2455 & 0.2768 \\
$\eta_{43}$ & 0.2842 & 0.2611 & 0.2207 & 0.2387 & 0.2768 \\
\hline
\end{tabular}

Table 16

The relative weight of the alternative $V_{1}$ to others.

\begin{tabular}{llllll}
\hline & $D_{1}$ & $D_{2}$ & $D_{3}$ & $D_{4}$ & $D_{5}$ \\
\hline$\eta_{12}^{*}$ & 1.0000 & 0.9296 & 0.8103 & 0.8639 & 0.9742 \\
$\eta_{13}^{*}$ & 1.0000 & 0.9296 & 0.7765 & 0.8400 & 0.9742 \\
$\eta_{14}^{*}$ & 1.0000 & 0.9296 & 0.7765 & 0.8400 & 0.9751 \\
\hline
\end{tabular}

Step 6. Determine the relative weight $\eta_{i k r}^{*}\left(\lambda_{r}\right)$ of the alternative $V_{i}$ to $V_{k}$ by using Eq. (20). The result is shown in Tables 16 to 19 .

Step 7. Determine the relative prospect dominance $\vartheta_{r}\left(V_{i}, V_{k}\right)$ and the dominance degree of the alternative $V_{i}(i=1,2,3,4)$ over the others, which are calculated as in Eq. (22) and (21), respectively. The result is shown in Tables 20 to 23. ( $\alpha=0.88, \beta=0.88, \theta=2.25$, which derive from the experiment of Kahneman, 1992). 
Table 17

The relative weight of the alternative $V_{2}$ to others.

\begin{tabular}{llllll}
\hline & $D_{1}$ & $D_{2}$ & $D_{3}$ & $D_{4}$ & $D_{5}$ \\
\hline$\eta_{21}^{*}$ & 1.0000 & 0.9223 & 0.7794 & 0.8431 & 0.9788 \\
$\eta_{23}^{*}$ & 1.0000 & 0.9189 & 0.7765 & 0.8400 & 0.9751 \\
$\eta_{24}^{*}$ & 1.0000 & 0.9189 & 0.7765 & 0.8400 & 0.9751 \\
\hline
\end{tabular}

Table 18

The relative weight of the alternative $V_{3}$ to others.

\begin{tabular}{llllll}
\hline & $D_{1}$ & $D_{2}$ & $D_{3}$ & $D_{4}$ & $D_{5}$ \\
\hline$\eta_{31}^{*}$ & 1.0000 & 0.9223 & 0.8133 & 0.8671 & 0.9788 \\
$\eta_{32}^{*}$ & 1.0000 & 0.9330 & 0.8133 & 0.8671 & 0.9779 \\
$\eta_{34}^{*}$ & 1.0000 & 0.9330 & 0.8133 & 0.8671 & 0.9788 \\
\hline
\end{tabular}

Table 19

The relative weight of the alternative $V_{4}$ to others.

\begin{tabular}{llllll}
\hline & $D_{1}$ & $D_{2}$ & $D_{3}$ & $D_{4}$ & $D_{5}$ \\
\hline$\eta_{41}^{*}$ & 1.0000 & 0.9223 & 0.8133 & 0.8671 & 0.9779 \\
$\eta_{42}^{*}$ & 1.0000 & 0.9330 & 0.8133 & 0.8671 & 0.9779 \\
$\eta_{43}^{*}$ & 1.0000 & 0.9189 & 0.7765 & 0.8400 & 0.9742 \\
\hline
\end{tabular}

Table 20

The relative prospect dominance of the alternative $V_{1}$ to others.

\begin{tabular}{llllll}
\hline & $D_{1}$ & $D_{2}$ & $D_{3}$ & $D_{4}$ & $D_{5}$ \\
\hline$\vartheta_{12}$ & -0.1117 & 0.0128 & 0.0036 & 0.0018 & -0.6653 \\
$\vartheta_{13}$ & -0.6741 & 0.0037 & -0.5687 & -0.6344 & -0.2589 \\
$\vartheta_{14}$ & -0.4153 & 0.0092 & -0.1190 & -0.0805 & 0.0003 \\
\hline
\end{tabular}

Table 21

The relative prospect dominance of the alternative $V_{2}$ to others.

\begin{tabular}{llllll}
\hline & $D_{1}$ & $D_{2}$ & $D_{3}$ & $D_{4}$ & $D_{5}$ \\
\hline$\vartheta_{21}$ & 0.0024 & -0.6960 & -0.2647 & -0.1138 & 0.0136 \\
$\vartheta_{23}$ & -0.5964 & -0.5483 & -0.7729 & -0.7117 & 0.0093 \\
$\vartheta_{24}$ & -0.3323 & -0.2581 & -0.3566 & -0.1791 & 0.0138 \\
\hline
\end{tabular}

Step 8. Acquire the overall dominance degree of the alternative $V_{i}(i=1,2,3,4)$ from Eq. (23).

$$
\psi\left(V_{1}\right)=0.3045, \quad \psi\left(V_{2}\right)=0, \quad \psi\left(V_{3}\right)=1, \quad \psi\left(V_{4}\right)=0.3883
$$


Table 22

The relative prospect dominance of the alternative $V_{3}$ to others.

\begin{tabular}{llllll}
\hline & $D_{1}$ & $D_{2}$ & $D_{3}$ & $D_{4}$ & $D_{5}$ \\
\hline$\vartheta_{31}$ & 0.0145 & -0.1994 & 0.0077 & 0.0099 & 0.0053 \\
$\vartheta_{32}$ & 0.0128 & 0.0101 & 0.0105 & 0.0111 & -0.4568 \\
$\vartheta_{34}$ & 0.0068 & 0.0062 & 0.0065 & 0.0091 & 0.0055 \\
\hline
\end{tabular}

Table 23

The relative prospect dominance of the alternative $V_{4}$ to others.

\begin{tabular}{llllll}
\hline & $D_{1}$ & $D_{2}$ & $D_{3}$ & $D_{4}$ & $D_{5}$ \\
\hline$\vartheta_{41}$ & 0.0089 & -0.4996 & 0.0016 & 0.0013 & -0.0164 \\
$\vartheta_{42}$ & 0.0071 & 0.0047 & 0.0048 & 0.0028 & -0.6735 \\
$\vartheta_{43}$ & -0.3158 & -0.3370 & -0.4820 & -0.5792 & -0.2680 \\
\hline
\end{tabular}

Step 9. Rank the overall dominance degree $\psi\left(V_{i}\right), i=1,2,3,4$.

$$
\psi\left(V_{3}\right)>\psi\left(V_{4}\right)>\psi\left(V_{1}\right)>\psi\left(V_{2}\right) .
$$

So, the alternative $V_{3}$ is the best one.

\subsection{Comparative Analysis}

In the following, we take into account the classical TODIM method (Wei, 2018), the VIKOR method (Meksavang et al., 2019), the picture fuzzy weighted cross-entropy method (Wei, 2016), the projection model (Wei et al., 2018), the MULTIMOORA method (Lin et al., 2020) and the EDAS method (Li et al., 2019) to test the efficiency of the improved TODIM, respectively.

\subsubsection{Comparison with the Classical TODIM}

Firstly, we take into account the classical TODIM (Wei, 2018) to verify the usability of the improved TODIM method proposed in this article. The final results of these two methods have a certain similarity that $V_{3}$ is confirmed to be the optimal alternative. However, there are some pivotal differences between the new improved TODIM method and the classical TODIM method. The new method provides a more detailed description of the mental processes of decision makers. In addition, beyond all questions, the introduction of weight calculation method further deepens the scientificity of the new method. The relevant process and results are shown as follows.

Step 1. We can use the same method to process data, like Section 4.1 from step 1 to step 4, obtaining the weighting vector of attributes $\lambda=(0.2368,0.2054,0.1546,0.1765,0.2266)$ and normalized Group score matrix $X$ shown in Table 11. 
Table 24

The dominance degree of the alternative $V_{1}$ to others.

\begin{tabular}{llllll}
\hline & $D_{1}$ & $D_{2}$ & $D_{3}$ & $D_{4}$ & $D_{5}$ \\
\hline$\vartheta_{12}$ & -0.7268 & 0.0459 & 0.0209 & 0.0144 & -2.0175 \\
$\vartheta_{13}$ & -2.0330 & 0.0224 & -1.9784 & -2.0601 & -1.1886 \\
$\vartheta_{14}$ & -1.5436 & 0.0377 & -0.8134 & -0.6376 & 0.0059 \\
\hline
\end{tabular}

Table 25

The dominance degree of the alternative $V_{2}$ to others.

\begin{tabular}{llllll}
\hline & $D_{1}$ & $D_{2}$ & $D_{3}$ & $D_{4}$ & $D_{5}$ \\
\hline$\vartheta_{21}$ & 0.0181 & -2.1221 & -1.2833 & -0.7775 & 0.0481 \\
$\vartheta_{23}$ & -1.8986 & -1.8523 & -2.3581 & -2.2019 & 0.0389 \\
$\vartheta_{24}$ & -1.3618 & -1.2072 & -1.5194 & -1.0055 & 0.0485 \\
\hline
\end{tabular}

Table 26

The dominance degree of the alternative $V_{3}$ to others.

\begin{tabular}{llllll}
\hline & $D_{1}$ & $D_{2}$ & $D_{3}$ & $D_{4}$ & $D_{5}$ \\
\hline$\vartheta_{31}$ & 0.0507 & -1.0356 & 0.0322 & 0.0383 & 0.0284 \\
$\vartheta_{32}$ & 0.0473 & 0.0400 & 0.0384 & 0.0409 & -1.6303 \\
$\vartheta_{34}$ & 0.0330 & 0.0304 & 0.0293 & 0.0364 & 0.0290 \\
\hline
\end{tabular}

Table 27

The dominance degree of the alternative $V_{4}$ to others.

\begin{tabular}{llllll}
\hline & $D_{1}$ & $D_{2}$ & $D_{3}$ & $D_{4}$ & $D_{5}$ \\
\hline$\vartheta_{41}$ & 0.0385 & -1.7453 & 0.0132 & 0.0118 & -0.2469 \\
$\vartheta_{42}$ & 0.0339 & 0.0261 & 0.0247 & 0.0187 & -2.0326 \\
$\vartheta_{43}$ & -1.3230 & -1.4048 & -1.8034 & -1.9590 & -1.2140 \\
\hline
\end{tabular}

Step 2. Determine the dominance degree using Eq. (24). And the result is shown in Tables 24 to 27 .

$$
\vartheta_{r}\left(V_{i}, V_{k}\right)= \begin{cases}\sqrt{\lambda_{r} \cdot\left(x_{i r}-x_{k r}\right) / \sum_{r=1}^{g} \lambda_{r}}, & \text { if } x_{i r}>x_{k r}, \\ 0, & \text { if } x_{i r}=x_{k r}, \\ -\theta \sqrt{\left(\sum_{r=1}^{g} \lambda_{r}\right) \cdot\left(x_{k r}-x_{i r}\right) / \lambda_{r},}, & \text { if } x_{i r}<x_{k r} .\end{cases}
$$

Step 3. Acquire the overall dominance degree of the alternative $V_{i}(i=1,2,3,4)$ from Eq. (23).

$$
\psi\left(V_{1}\right)=0.3006, \quad \psi\left(V_{2}\right)=0, \quad \psi\left(V_{3}\right)=1, \quad \psi\left(V_{4}\right)=0.3852
$$


Table 28

The collective picture fuzzy evaluation matrix $U$.

\begin{tabular}{llllll}
\hline & $D_{1}$ & $D_{2}$ & $D_{3}$ & $D_{4}$ & $D_{5}$ \\
\hline$V_{1}$ & $(0.5523,0.1029,0.2197)$ & $(0.8160,0.0260,0.1200)$ & $(0.6335,0.0804,0.2351)$ & $(0.6145,0.0943,0.2457)$ & $(0.5352,0.1434,0.2175)$ \\
$V_{2}$ & $(0.5689,0.1684,0.1966)$ & $(0.5360,0.1582,0.0867)$ & $(0.5158,0.2177,0.1794)$ & $(0.5021,0.2034,0.1650)$ & $(0.6971,0.0727,0.1394)$ \\
$V_{3}$ & $(0.7290,0.0335,0.1418)$ & $(0.7261,0.0664,0.0958)$ & $(0.7243,0.0504,0.1563)$ & $(0.7099,0.0749,0.1447)$ & $(0.6077,0.0857,0.1723)$ \\
$V_{4}$ & $(0.6490,0.1027,0.1277)$ & $(0.6335,0.1264,0.1038)$ & $(0.5793,0.1958,0.1367)$ & $(0.6045,0.0671,0.2128)$ & $(0.4988,0.2409,0.1817)$ \\
\hline
\end{tabular}

Table 29

The distance from each scheme to the perfect point.

\begin{tabular}{llllll}
\hline & $D_{1}$ & $D_{2}$ & $D_{3}$ & $D_{4}$ & $D_{5}$ \\
\hline$V_{1}$ & 0.2650 & 0.0000 & 0.1631 & 0.1805 & 0.2430 \\
$V_{2}$ & 0.2846 & 0.4700 & 0.3127 & 0.3117 & 0.0000 \\
$V_{3}$ & 0.0000 & 0.1712 & 0.0000 & 0.0000 & 0.1342 \\
$V_{4}$ & 0.1411 & 0.2981 & 0.2468 & 0.1699 & 0.3157 \\
\hline
\end{tabular}

Step 4. Rank the overall dominance degree $\psi\left(V_{i}\right), i=1,2,3,4$.

$$
\begin{aligned}
& \psi\left(V_{3}\right)>\psi\left(V_{4}\right)>\psi\left(V_{1}\right)>\psi\left(V_{2}\right), \\
& V_{3}>V_{4}>V_{1}>V_{2} .
\end{aligned}
$$

So, the alternative $V_{3}$ is the best one.

\subsubsection{Comparison with the VIKOR Method}

In the VIKOR (Meksavang et al., 2019) method, the collective picture fuzzy evaluation matrix is shown in Table 28. The positive ideal in different attributes is as follows: $u_{1}^{+}=(0.7290,0.0335,0.1418), u_{2}^{+}=(0.8160,0.0260,0.1200), u_{3}^{+}=(0.7243$, $0.0504,0.1563), u_{4}^{+}=(0.7099,0.0749,0.1447), u_{5}^{+}=(0.6971,0.0727,0.1394)$ and the negative is: $u_{1}^{-}=(0.5523,0.1029,0.2197), u_{2}^{-}=(0.5360,0.1582,0.0867), u_{3}^{-}=$ $(0.5158,0.2177,0.1794), u_{4}^{-}=(0.5021,0.2034,0.1650), u_{5}^{-}=(0.4988,0.2409$, $0.1817)$. The distance from each scheme to the perfect point is shown in Table 29. And the values $S_{i}(i=1,2,3,4)$ and $R_{i}(i=1,2,3,4)$ are as follows: $S_{1}=0.6600, S_{2}=1.0086$, $S_{3}=0.2474, S_{4}=0.8842 ; R_{1}=0.2368, R_{2}=0.3642, R_{3}=0.1326, R_{4}=0.2699$. The $Q_{i}(i=1,2,3,4)$ index is as follows: $Q_{1}=0.4959, Q_{2}=1, Q_{3}=0, Q_{4}=0.7147$, $Q_{3}<Q_{1}<Q_{4}<Q_{2}$. Therefore, there is $V_{3}>V_{1}>V_{4}>V_{2}$. The alternative $V_{3}$ is the optimal one.

\subsubsection{Comparison with the Picture Fuzzy Weighted Cross-Entropy Method}

In this part, we list the vital process of picture fuzzy weighted cross-entropy method (Wei, 2016). According to the principle of maximum positive membership degree and minimum negative as well as neutral membership degree, we can get the information of the ideal alternative

$V^{+}=\left(\begin{array}{l}(0.7290,0.0335,0.1277),(0.8160,0.0260,0.0867),(0.7243,0.0504,0.1367), \\ (0.7099,0.0671,0.1447),(0.6971,0.0727,0.1394)\end{array}\right)$. 
Meanwhile, the picture fuzzy weighted cross-entropy between $V_{i}(i=1,2,3,4)$ and $V^{+}$ is as following: $C\left(V_{1}, V^{+}\right)=0.0179, C\left(V_{2}, V^{+}\right)=0.0373, C\left(V_{3}, V^{+}\right)=0.0034$, $C\left(V_{4}, V^{+}\right)=0.0271$. The smallest picture fuzzy weighted cross-entropy $C\left(V_{3}, V^{+}\right)$corresponds with the best alternative $V_{3}$.

\subsubsection{Comparison with the Projection Model}

The following describes the key information about the projection model (Wei et al., 2018). In accordance to the identical principle with picture fuzzy weighted cross-entropy method,

$$
V^{+}=\left(\begin{array}{l}
(0.7290,0.0335,0.1277),(0.8160,0.0260,0.0867),(0.7243,0.0504,0.1367), \\
(0.7099,0.0671,0.1447),(0.6971,0.0727,0.1394)
\end{array}\right)
$$

is considered as the ideal alternative. The projection $V_{i}(i=1,2,3,4)$ on $V^{+}$can easily be obtained. The results are shown as follows: $\operatorname{Prj}_{V^{+}}\left(V_{1}\right)=0.3000, \operatorname{Prj}_{V^{+}}\left(V_{2}\right)=0.2758$, $\operatorname{Prj}_{V^{+}}\left(V_{3}\right)=0.3253, \operatorname{Prj}_{V^{+}}\left(V_{4}\right)=0.2846$. The alternative $V_{3}$ with biggest $\operatorname{Prj}_{V^{+}}\left(V_{3}\right)$ is the best one.

\subsubsection{Comparison with the MULTIMOORA Method}

The main idea of the MULTIMOORA method (Lin et al., 2020) is to dispose of the fundamental information in different way. Finally, ranking value matrix and the corresponding ranking order matrix come into being. The ranking value matrix is

$$
T=\begin{gathered}
T_{1} \\
V_{1} \\
V_{2} \\
V_{3} \\
V_{4}
\end{gathered}\left(\begin{array}{lll}
0.4200 & 0.2368 & 1.2911 \\
0.4174 & 0.2557 & 1.2778 \\
0.5545 & 0.0750 & 1.4190 \\
0.4408 & 0.2266 & 1.2999
\end{array}\right)
$$

and the ranking order matrix is

$$
G=\begin{gathered}
G_{1} \\
V_{1} \\
V_{2} \\
V_{2} \\
V_{3} \\
V_{4}
\end{gathered}\left(\begin{array}{lll}
3 & 3 & 3 \\
4 & 4 & 4 \\
1 & 1 & 1 \\
2 & 2 & 2
\end{array}\right)
$$

Based on these two matrices, we can figure out the final ranking score of alternative $V_{i}$ $(i=1,2,3,4): B\left(V_{1}\right)=0.0204, B\left(V_{2}\right)=-0.1486, B\left(V_{3}\right)=0.4369, B\left(V_{4}\right)=0.1833$. Therefore, the ranking result is $V_{3}>V_{4}>V_{1}>V_{2}$ and the alternative $V_{3}$ is first-rank.

\subsubsection{Comparison with the EDAS Method}

The Table 30 shows the main results of EDAS method (Li et al., 2019). And it is obvious that the alternative $V_{3}$ is the optimal which keeps in line with the new TODIM method proposed in this paper. 
Table 30

The outcome about EDAS method.

\begin{tabular}{lllll}
\hline & $V_{1}$ & $V_{2}$ & $V_{3}$ & $V_{4}$ \\
\hline SP & 0.0212 & 0.0094 & 0.0449 & 0.0075 \\
SN & 0.0317 & 0.0430 & 0.0008 & 0.0295 \\
NSP & 0.4721 & 0.2094 & 1 & 0.1668 \\
NSN & 0.2626 & 0 & 0.9805 & 0.3138 \\
AS & 0.3674 & 0.1047 & 0.9903 & 0.2403 \\
The ordering & & \multicolumn{2}{c}{$V_{3}>V_{1}>V_{4}>V_{2}$} & \\
\hline
\end{tabular}

Table 31

The comparison.

\begin{tabular}{ll}
\hline Method & The ranking result \\
\hline Classical TODIM & $V_{3}>V_{4}>V_{1}>V_{2}$ \\
VIKOR & $V_{3}>V_{1}>V_{4}>V_{2}$ \\
Picture fuzzy weighted cross-entropy & $V_{3}>V_{1}>V_{4}>V_{2}$ \\
Projection model & $V_{3}>V_{1}>V_{4}>V_{2}$ \\
MULTIMOORA & $V_{3}>V_{4}>V_{1}>V_{2}$ \\
EDAS & $V_{3}>V_{1}>V_{4}>V_{2}$ \\
Improved TODIM & $V_{3}>V_{4}>V_{1}>V_{2}$ \\
\hline
\end{tabular}

\subsubsection{Contrastive Analysis}

We put all the results from different methods together in Table 31. Either way, the alternative $V_{3}$ is always the best one, which fully proves the reliability of the new proposed method. Furthermore, the improved picture fuzzy TODIM method, which has unparalleled superiority in meticulously describing the decision maker's psychological states, is proposed in this paper for further improvement of TODIM method based on CPT. In addition, the improved picture fuzzy TODIM method gives logical method to obtain the attribute weights, eliminating the subjectivity of the information of attribute weight directly given by the decision maker. Therefore, it is more widely applicable in handling the MAGDM issues.

\section{Conclusions}

The TODIM method just focuses on MADM in real number, and doesn't distinguish positive and negative attributes. Moreover, it supposes that the initial attributes weight vector is directly afforded by the expert. In this article, we expound the application of extended TODIM based on Cumulative Prospect Theory under picture fuzzy multiple attribute group decision making. First of all, we briefly sort out the basic knowledge (e.g. PFSs and PFNs) and introduce the extended TODIM. In addition, we adopt information entropy, which is used to identify the attributes weighting vector, to improve the availability of the TODIM method. At last, we exercise the improved TODIM into a numerical case and testify the effectiveness of this new method by means of comparing its results with other methods' results. In years to come, the improved TODIM method should saturate 
numerous other fields and uncertainty environments (Deng and Gao, 2019; Gao et al., 2019; He et al., 2019; Li and Lu, 2019; Lu and Wei, 2019; Wang J. et al., 2019; Wang, 2019; Wei et al., 2019b; Wu et al., 2019a, 2019b). And we will also continue to explore the application of this proposed TODIM method in other fields (Lu et al., 2020; Wang et al., 2020; Wei Y. et al., 2020) and seek more scientific methods to solve the multi-attribute group decision problems (Liu and Liu, 2019; Liu and Wang, 2014; Liu et al., 2018).

\section{Funding}

This paper is supported by the Natural Science Foundation of China (No. 71571128).

\section{References}

Atanassov, K.T. (1986). Intuitionistic fuzzy sets. Fuzzy Sets and Systems, 20, 87-96.

Biswas, A., Sarkar, B. (2019). Interval-valued Pythagorean fuzzy TODIM approach through point operatorbased similarity measures for multicriteria group decision making. Kybernetes, 48, 496-519.

Brauers, W.K.M., Zavadskas, E.K. (2006). The MOORA method and its application to privatization in a transition economy. Control and Cybernetics, 35, 445-469.

Cuong, B.C. (2014). Picture fuzzy sets. Journal of Computer Science and Cybernetics, 30, 409-420.

Deng, X.M., Gao, H. (2019). TODIM method for multiple attribute decision making with 2-tuple linguistic Pythagorean fuzzy information. Journal of Intelligent \& Fuzzy Systems, 37, 1769-1780.

Gao, H., Lu, M., Wei, Y. (2019). Dual hesitant bipolar fuzzy hamacher aggregation operators and their applications to multiple attribute decision making. Journal of Intelligent \& Fuzzy Systems, 37, 5755-5766.

Gao, H., Ran, L.G., Wei, G.W., Wei, C., Wu, J. (2020). VIKOR method for MAGDM based on q-rung intervalvalued orthopair fuzzy information and its application to supplier selection of medical consumption products. International Journal of Environmental Research and Public Health, 17, 525.

Garg, H. (2017). Some picture fuzzy aggregation operators and their applications to multicriteria decisionmaking. Arabian Journal for Science and Engineering, 42, 5275-5290.

He, T.T., Wei, G.W., Lu, J.P., Wei, C., Lin, R. (2019). Pythagorean 2-tuple linguistic Taxonomy method for supplier selection in medical instrument industries. International Journal of Environmental Research and Public Health, 16, 4875.

Ju, Y.B., Ju, D.W., Gonzalez, E., Giannakis, M., Wang, A.H. (2019). Study of site selection of electric vehicle charging station based on extended GRP method under picture fuzzy environment. Computers \& Industrial Engineering, 135, 1271-1285.

Kahneman, T. (1992). Advances in prospect theory: cumulative representation of uncertainty. Journal of Risk and Uncertainty, 5, 297-323.

Keshavarz Ghorabaee, M., Zavadskas, E.K., Olfat, L., Turskis, Z. (2015). Multi-criteria inventory classification using a new method of evaluation based on distance from average solution (EDAS). Informatica, 26, 435-451.

Khan, S., Abdullah, S., Abdullah, L., Ashraf, S. (2019). Logarithmic aggregation operators of picture fuzzy numbers for multi-attribute decision making problems. Mathematics, 7, 19.

Gomes, L.F.A.M., Lima, M.M.P.P. (1992). TODIM: basics and application to multicriteria ranking of projects with environmental impacts. Foundations of Computing and Decision Sciences, 16, 113-127.

Li, X., Ju, Y.B., Ju, D.W., Zhang, W.K., Dong, P.W., Wang, A.H. (2019). Multi-attribute group decision making method based on EDAS under picture fuzzy environment. IEEE Access, 7, 141179-141192.

Li, Z.X., Lu, M. (2019). Some novel similarity and distance and measures of Pythagorean fuzzy sets and their applications. Journal of Intelligent \& Fuzzy Systems, 37, 1781-1799.

Liang, D.C., Wang, M.W., Xu, Z.S., Liu, D. (2020). Risk appetite dual hesitant fuzzy three-way decisions with TODIM. Information Sciences, 507, 585-605.

Liang, W.Z., Zhao, G.Y., Luo, S.Z. (2018). An integrated EDAS-ELECTRE method with picture fuzzy information for cleaner production evaluation in gold mines. IEEE Access, 6, 65747-65759.

Liang, W.Z., Zhao, G.Y., Wu, H., Chen, Y. (2019). Assessing the risk degree of goafs by employing hybrid TODIM method under uncertainty. Bulletin of Engineering Geology and the Environment, 78, 3767-3782. 
Liang, Y.Y., Tu, Y., Ju, Y.B., Shen, W.J. (2019). A multi-granularity proportional hesitant fuzzy linguistic TODIM method and its application to emergency decision making. International Journal of Disaster Risk Reduction, 36, 11.

Lin, M.W., Huang, C., Xu, Z.S. (2020). MULTIMOORA based MCDM model for site selection of car sharing station under picture fuzzy environment. Sustainable Cities and Society, 53.

Liu, P.D., Wang, Y.M. (2014). Multiple attribute group decision making methods based on intuitionistic linguistic power generalized aggregation operators. Applied Soft Computing, 17, 90-104.

Liu, P.D., Zhang, X.H. (2018). A novel picture fuzzy linguistic aggregation operator and its application to group decision-making. Cognitive Computation, 10, 242-259.

Liu, P.D., Liu, W.Q. (2019). Multiple-attribute group decision-making based on power Bonferroni operators of linguistic $q$-rung orthopair fuzzy numbers. International Journal of Intelligent Systems, 34, 652-689.

Liu, P.D., Teng, F. (2019). Probabilistic linguistic TODIM method for selecting products through online product reviews. Information Sciences, 485, 441-455.

Liu, D.H., Liu, Y.Y., Wang, L.Z. (2019). Distance measure for Fermatean fuzzy linguistic term sets based on linguistic scale function: an illustration of the TODIM and TOPSIS methods. International Journal of Intelligent Systems, 34, 2807-2834.

Liu, Y., Zhang, H., Wu, Y., Dong, Y. (2019). Ranking range based approach to madm under incomplete context and its application in venture investment evaluation. Technological and Economic Development of Economy, 25, 877-899.

Liu, Z.M., Liu, P.D., Liang, X. (2018). Multiple attribute decision-making method for dealing with heterogeneous relationship among attributes and unknown attribute weight information under q-rung orthopair fuzzy environment. International Journal of Intelligent Systems, 33, 1900-1928.

Lu, J.P., Wei, C. (2019). TODIM method for performance appraisal on social-integration-based rural reconstruction with interval-valued intuitionistic fuzzy information. Journal of Intelligent \& Fuzzy Systems, 37 , 1731-1740.

Lu, J.P., Tang, X.Y., Wei, G.W., Wei, C., Wei, Y. (2019). Bidirectional project method for dual hesitant Pythagorean fuzzy multiple attribute decision-making and their application to performance assessment of new rural construction. International Journal of Intelligent Systems, 34, 1920-1934.

Lu, J.P., He, T.T., Wei, G.W., Wu, J., Wei, C. (2020). Cumulative prospect theory: performance evaluation of government purchases of home-based elderly-care services using the Pythagorean 2-tuple linguistic TODIM method. International Journal of Environmental Research and Public Health, 17, 1939.

Ma, X.L., Zhan, J.M., Khan, M., Zeeshan, M., Anis, S., Awan, A.S. (2019). Complex fuzzy sets with applications in signals. Computational \& Applied Mathematics, 38, 34.

Meksavang, P., Shi, H., Lin, S.M., Liu, H.C. (2019). An extended picture fuzzy VIKOR approach for sustainable supplier management and its application in the Beef industry. Symmetry-Basel, 11, 19.

Mishra, A.R., Rani, P. (2018). Biparametric information measures-based TODIM technique for interval-valued intuitionistic fuzzy environment. Arabian Journal for Science and Engineering, 43, 3291-3309.

Opricovic, S., Tzeng, G.H. (2004). Compromise solution by MCDM methods: a comparative analysis of VIKOR and TOPSIS. European Journal of Operational Research, 156, 445-455.

Pamucar, D., Cirovic, G. (2015). The selection of transport and handling resources in logistics centers using multi-attributive border approximation area comparison (MABAC). Expert Systems with Applications, 42, 3016-3028.

Ren, Z.L., Xu, Z.S., Wang, H. (2017). An extended TODIM method under probabilistic dual hesitant fuzzy information and its application on enterprise strategic assessment. In: IEEE International Conference on Industrial Engineering and Engineering Management, 1464-1468.

Sindhu, M.S., Rashid, T., Kashif, A. (2019). Modeling of linear programming and extended TOPSIS in decision making problem under the framework of picture fuzzy sets. PLOS ONE, 14, 13.

Tian, X.L., Xu, Z.S., Gu, J. (2019). An extended TODIM based on cumulative prospect theory and its application in venture capital. Informatica, 30, 413-429.

Wang, F., Li, X.T., Zhao, J., Chen, S.H. (2019). A TODIM. SIR method for multiple attribute decision making with interval grey uncertain linguistic based on a new distance measure. Journal of Intelligent \& Fuzzy Systems, 37, 1569-1581.

Wang, J., Gao, H., Lu, M. (2019). Approaches to strategic supplier selection under interval neutrosophic environment. Journal of Intelligent \& Fuzzy Systems, 37, 1707-1730.

Wang, L., Zhang, H.Y., Wang, J.Q., Li, L. (2018). Picture fuzzy normalized projection-based VIKOR method for the risk evaluation of construction project. Applied Soft Computing, 64, 216-226. 
Wang, P., Wang, J., Wei, G.W. (2019). EDAS method for multiple criteria group decision making under 2-tuple linguistic neutrosophic environment. Journal of Intelligent \& Fuzzy Systems, 37, 1597-1608.

Wang, P., Wang, J., Wei, G.W., Wu, J., Wei, C., Wei, Y. (2020). CODAS method for multiple attribute group decision making under 2-tuple linguistic neutrosophic environment. Informatica, 31, 161-184.

Wang, R. (2019). Research on the application of the financial investment risk appraisal models with some interval number muirhead mean operators. Journal of Intelligent \& Fuzzy Systems, 37, 1741-1752.

Wei, G. (2016). Picture fuzzy cross-entropy for multiple attribute decision making problems. Journal of Business Economics and Management, 17, 491-502.

Wei, G.W. (2017). Picture fuzzy aggregation operators and their application to multiple attribute decision making. Journal of Intelligent \& Fuzzy Systems, 33, 713-724.

Wei, G.W. (2018). TODIM method for picture fuzzy multiple attribute decision making. Informatica, 29, 555566.

Wei, G.W., Alsaadi, F.E., Hayat, T., Alsaedi, A. (2018). Projection models for multiple attribute decision making with picture fuzzy information. International Journal of Machine Learning and Cybernetics, 9, 713-719.

Wei, G.W., Wang, R., Wang, J., Wei, C., Zhang, Y. (2019a). Methods for evaluating the technological innovation capability for the high-tech enterprises with generalized interval neutrosophic number Bonferroni mean operators. IEEE Access, 7, 86473-86492.

Wei, G.W., Wei, C., Wu, J., Wang, H.J. (2019b). Supplier selection of medical consumption products with a probabilistic linguistic MABAC method. International Journal of Environmental Research and Public Health, 16, 5082.

Wei, Y., Nan, H., Wei, G. (2020). The impact of employee welfare on innovation performance: evidence from China's manufacturing corporations. International Journal of Production Economics, 228, 107753.

Wu, C., Zhang, D. (2019). Ranking products with IF-based sentiment word framework and TODIM method. Kybernetes, 48, 990-1010.

Wu, L.P., Gao, H., Wei, C. (2019a). VIKOR method for financing risk assessment of rural tourism projects under interval-valued intuitionistic fuzzy environment. Journal of Intelligent \& Fuzzy Systems, 37, 2001-2008.

Wu, L.P., Wang, J., Gao, H. (2019b). Models for competiveness evaluation of tourist destination with some interval-valued intuitionistic fuzzy Hamy mean operators. Journal of Intelligent \& Fuzzy Systems, 36, 56935709.

Wu, Y.N., Wang, J., Ji, S.Y., Song, Z.X., Ke, Y.M. (2019). Optimal investment selection of industrial and commercial rooftop distributed PV project based on combination weights and cloud-TODIM model from SMEs' perspectives. Journal of Cleaner Production, 234, 534-548.

Yu, W.Y., Zhang, Z., Zhong, Q.Y., Sun, L.L. (2017). Extended TODIM for multi-criteria group decision making based on unbalanced hesitant fuzzy linguistic term sets. Computers \& Industrial Engineering, 114, 316-328.

Yuan, J.H., Li, X.Y., Xu, C.B., Zhao, C.H., Liu, Y.X. (2019). Investment risk assessment of coal-fired power plants in countries along the Belt and Road initiative based on ANP-Entropy-TODIM method. Energy, 176, 623-640.

Zadeh, L.A. (1965). Fuzzy sets. Information and Control, 8, 338-356.

Zhang, D., Li, Y.L., Wu, C. (2019). An extended TODIM method to rank products with online reviews under intuitionistic fuzzy environment. Journal of the Operational Research Society, 13.

Zhang, Y.X., Xu, Z.S., Liao, H.C. (2019). Water security evaluation based on the TODIM method with probabilistic linguistic term sets. Soft Computing, 23, 6215-6230.

Zhang, Z., Guo, C.H., Martinez, L. (2017). Managing multigranular linguistic distribution assessments in largescale multiattribute group decision making. IEEE Transactions on Systems Man Cybernetics-Systems, 47, 3063-3076.

Zhang, Z., Yu, W., Martinez, L., Gao, Y. (2019). Managing multigranular unbalanced hesitant fuzzy linguistic information in multiattribute large-scale group decision making: a linguistic distribution-based approach. IEEE Transactions on Fuzzy Systems, 1-1.

Zhu, J.H., Shuai, B., Wang, R., Chin, K.S. (2019). Risk assessment for failure mode and effects analysis using the Bonferroni mean and TODIM method. Mathematics, 7, 17.

M. Zhao is currently a master's student at School of Business, Sichuan Normal University, Chengdu, 610101, PR China. 
G. Wei has an MSc and a PhD degrees in applied mathematics from SouthWest Petroleum University, and in business administration from School of Economics and Management, SouthWest Jiaotong University, China, respectively. From May 2010 to April 2012, he was a postdoctoral researcher at the School of Economics and Management, Tsinghua University, Beijing, China. He is a professor at the School of Business, Sichuan Normal University. He has published more than 100 papers in journals, books and conference proceedings including journals such as Omega, Decision Support Systems, Expert Systems with Applications, Applied Soft Computing, Knowledge and Information Systems, Computers \& Industrial Engineering, Knowledge-Based Systems, International Journal of Uncertainty, Fuzziness and Knowledge-Based Systems, International Journal of Computational Intelligence Systems and Information: An International Interdisciplinary Journal. He has published 1 book. He has participated in several scientific committees and serves as a reviewer in a wide range of journals including Computers \& Industrial Engineering, International Journal of Information Technology and Decision Making, Knowledge-Based Systems, Information Sciences, International Journal of Computational Intelligence Systems and European Journal of Operational Research. He is currently interested in aggregation operators, decision making and computing with words.

C. Wei has an MSc degree in applied mathematics from SouthWest Petroleum University. Now, he is a PhD student at School of Statistics, Southwestern University of Finance and Economics, Chengdu, 611130, PR China. He has published more than 10 papers in journals, such as International Journal of Intelligent Systems, Journal of Intelligent and Fuzzy Systems, IEEE Access, Mathematics, Information. He is currently interested in aggregation operators, decision making and computing with words.

J. Wu has a $\mathrm{PhD}$ degree in management science and engineering from Southwest Jiaotong University, China. He is a professor at the School of Statistics at Southwestern University of Finance and Economics, Chengdu, 611130, PR China.

Y. Guo has a $\mathrm{PhD}$ degree in management science and engineering from Southwest Jiaotong University, China. He is an associate professor at the School of Finance, Southwestern University of Finance and Economics, Chengdu, 610074, PR China. He is currently interested in forecasting in financial and decision making in financial markets. 